An interesting chapter (xviii) is devoted to the recently erupted island of Anak Krakatau, which first emerged above sea-level on January 26, 1928, and a list of the seeds and plants found on this 'baby' island by the author includes many coconuts, forty-one of which had germinated. These

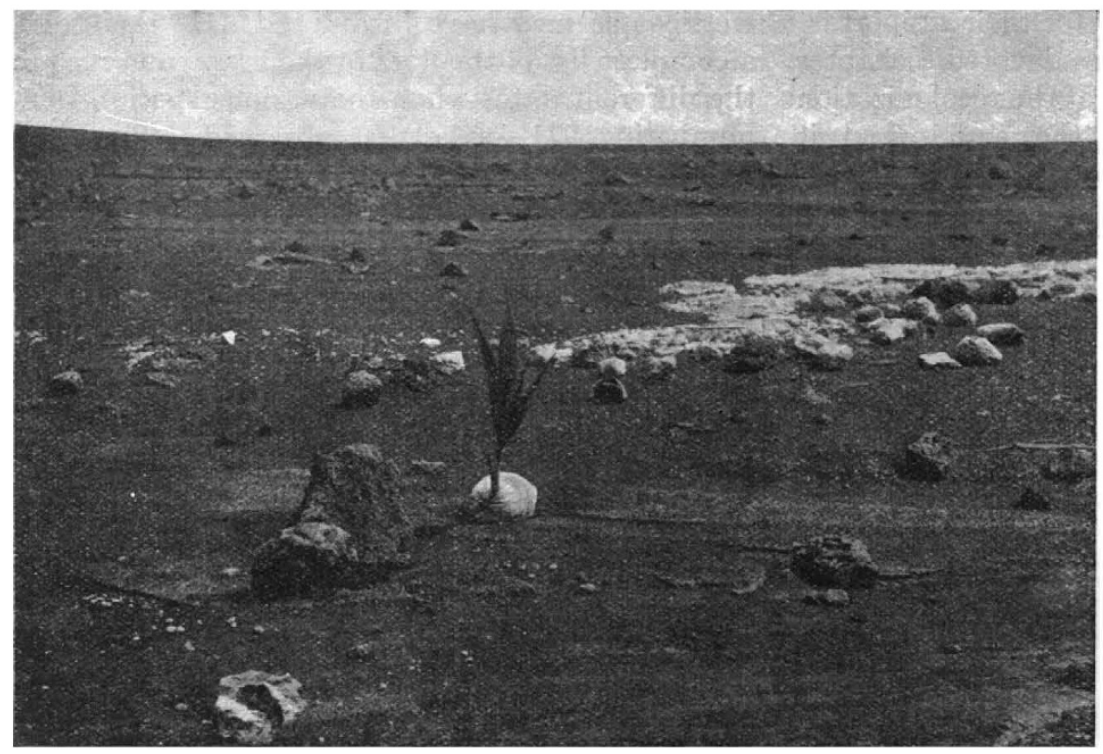

Fig. 4.

Anak Krakatau, May 1932. Photo by C. C. Reijnvaan.

no doubt will be destroyed during the next eruption, but the colonization of this new creation affords possibilities of a very interesting study.

Dr. Docters van Leeuwen's chapter (xxi) on Zoocecidia is one of the most valuable in the book, not only because he is a leading authority on the group, but also because these short-lived gallproducing insects and mites must have been destroyed by the eruption, so that all those now present on the island can only be immigrants.

No galls were found on the plants collected by Treub, though this does not prove that none had then arrived, but it is of interest that very few galls are known on the plants found by Treub on Krakatau in 1886. Dr. Docters van Leeuwen has collected no less than sixty galls on forty-four different plants on the islands. Since, then, it is inconceivable that these delicate insects can have survived the eruption, it is clear that the plants were the first immigrants, and when they had become established the gallproducers followed, being transported by the wind or ocean currents.

The value of the work is completed by the excellent bibliography and full index, and by the admirable illustrations, sixty-one in num. ber, showing various stages in the development of the vegetation on the islands.

Dr. Docters van Leeuwen has earned our grateful thanks for this convincing treatise-so well written in English-which he has most fittingly dedicated to the memory of Melchior Treub.
ARthur W. HIrL.

\title{
Prevention of Smoke and Dust Emission from Chimneys
}

$\mathrm{T}$ HE weight of coal consumed annually in Great Britain is approximately $\mathbf{1 6 5}$ million tons, and of this only a small proportion is burned without smoke or grit being discharged into the atmosphere. It is, however, not possible to make even an approximate estimate of the extent to which the use of coal is responsible for atmospheric pollution and its attendant evils, on account of the wide differences which occur in the nature and quantity of smoke or grit produced by the combustion of unit weight of fuel. Both depend upon the type of coal used, the purpose for which it is burned and the skill employed in burning it, all of which vary from case to case.
When coal is burned on a domestic grate-and some 35 million tons are used annually for household purposes-the smoke produced consists of partially cracked tarry vapours formed by the distillation of a portion of the volatile matter in the coal. The quantity depends, of course, upon the type of grate and the nature of the fuel used. To burn soft bituminous coal smokelessly in an open fireplace is extremely difficult, but endeavours are being made to devise a suitable grate. Should they not be successful, it will be necessary, if smoke is to be avoided, either to abandon the open fireplace altogether, or to increase still further the use of smokeless 
fuel, such as low temperature coke, and gas or electricity.

The same type of smoke as that produced from domestic fireplaces may also be emitted from small industrial furnaces. In this case, however, there is no real difficulty in avoiding incomplete combustion. Its cause is usually either incorrect operation or the fact that the furnaces are being forced beyond their capacity. Reservations must be made in favour of certain metallurgical and ceramic processes requiring a reducing atmosphere, but even in these, improvements in the design of the furnace, care in the selection of the fuel, and scientific operation can often mitigate the nuisance. Generally speaking, therefore, the excessive emission of tarry vapours or soot from an industrial furnace is inexcusable. Nevertheless, many industrial furnaces are sources of a form of atmospheric pollution far more difficult to prevent than that due to incomplete combustion, namely, the dust and grit carried through the furnace by the draught.

In order to obtain sufficiently high rates of heat liberation in the space available, the air supplied for combustion may pass through the fuel bed at such a velocity that it will carry with it small solid particles of ash and unburnt or partially burnt fuel, as distinct from smoke. These may be relatively large, up to say $\frac{1}{8}$ in. in diameter, and as, for economic reasons, the fuel used may be small in size and contain a considerable percentage of ash, the weight of solid material carried over may be high. In the case of large boilers, such as those found in power stations, the combustion chambers are so designed that the weight of carbon discharged in the flue gases is relatively small, but a large proportion of the ash in the coal is inevitably carried through the boiler. As the fuel often contains 10 per cent or more of ash, the weight of dust and grits discharged daily from a boiler burning several tons of coal per hour is appreciable.

During the last few years, an increasing number of the furnaces used in boilers and for metallurgical purposes have been fired with powdered coal. With this fuel most of the ash particles are less than 10 microns in diameter, with the result that, unless some form of dust-arresting apparatus is employed, most of the ash in the fuel will find its way up the chimney. This, more than any other isolated fact, has probably been the origin of the present increased interest in the prevention of dust emission.

The most obvious way of reducing the amount of dust leaving a furnace is to reduce the amount of ash supplied to it, that is, to use cleaned coal. It is gradually becoming realized that dirty coal is not necessarily cheap coal, and the use of cleaned coal is rapidly increasing. Nevertheless, it is not possible to clean boiler coal so as to reduce its ash content below a certain figure, say between 3 and 5 per cent on the average, so this method can provide only a partial cure.

A second method is to retain the ash in the furnace, and this is done to some extent in stokerfired furnaces in which a large proportion of the ash fuses on the grate and is removed in lumps as clinker. The same method has been tried in certain pulverized fuel furnaces known as 'slag tap' furnaces, in which conditions are so arranged that the ash particles are caused to fuse into a pool at the base of the furnace, from which molten slag is run off at intervals. The arrangement is, however, not popular in Great Britain.

The remaining method, and the most generally used, is to remove as much dust as possible from the flue gases during their passage from the boiler to the chimney. For this purpose various types of dust extraction plant have been evolved, but their use is not so general as might be desired, mainly on account of expense.

In a few industrial processes the dust discharged has a commercial value and pays for its collection, but in most plants, including boiler furnaces, the dust produced is worthless and the cost of its collection is a complete loss, entailing not only capital, power and maintenance charges, but also the cost of disposing of the material caught.

Commercial dust extraction plants may be divided into two main groups, namely, dry and wet. The dry types include $(a)$ those making use of gravity alone, $(b)$ those using centrifugal force and $(c)$ the electrostatic type ; in these the collected material is removed in the form of a dry powder. In the wet types the dust is brought into contact with water sprays or films and is removed from the plant as a 'slurry'.

The simplest form of dry dust collector is a large empty chamber in which the solid particles settle out of the flue gases under the action of gravity. For such a chamber to be effective, a particle must be able to fall through the height of the chamber in less time than it takes the gas to travel through it. Now the rate of fall is proportional to the square of the radius of the particle, and the volume of flue gas leaving a boiler of only moderate size is very large; hence, in practice, an efficient settling chamber of reasonable dimensions is possible only with small boilers emitting large grits. Against this, the simple settling chamber has the great advantages that it requires no special fans or machinery and that no additional power costs are involved.

Many methods of reducing the size of settling chambers have been employed with varying success. Of these the most effective is the use of baffles or other devices which assist dust separation 
by causing the flue gases to undergo sudden changes of velocity and direction. The application of such devices is, howéver, limited by the fact that they increase the small pressure drop in the flue gases which constitutes the main advantage of the settling chamber. If fan power becomes necessary, more efficient forms of collector are available.

When a pressure drop of the order of about 2 in. water gauge or more is permissible, it is possible to use a form of separator in which gravity is replaced by centrifugal force. The simplest device of this type is the well-known cyclone, in which the flue gases enter a short cylinder tangentially and leave through a central axial opening. The dust is thrown out by centrifugal force and is collected in an inverted cone below the cylinder, being finally withdrawn through a suitable valve at the base.

The common cyclone has been subject to many modifications with the object of increasing its efficiency and decreasing the capital and power costs involved in its use. In addition, a great variety of other centrifugal devices have been evolved, for some of which high efficiencies are claimed, even with pulverized fuel dust. All these apparatus have the advantage of comparative low cost and simplicity, but all are subject to certain inherent limitations: they are more effective with large than with small particles, and their efficiency depends upon the flue gases being constrained to flow at a high velocity in a circle of small radius. As a result of these limitations, centrifugal separators may in practice be regarded as eminently suitable for arresting the relatively large grits associated with hand and mechanical stoker firing, but distinctly less satisfactory for dealing with the very fine dust from powdered fuel furnaces.

During recent years, particularly as a result of the growing use of powdered fuel, increasing attention has been given to a form of dry dust extractor which, although more costly than the types already mentioned, has the great advantage of being able to deal with very fine dust as well as with grits, namely, the electrostatic precipitator. In this device the dust-laden flue gases are caused to flow between two electrodes, one of which is charged to a high negative potential and the other earthed. As a result of ionic discharge between the electrodes, the dust particles become negatively charged and move towards the earthed electrodes to which they give up their charge, and upon which they are collected. They are then caused to fall into some form of hopper from which they are removed from the system.

The method has the advantages of low pressure drop, low maintenance charges, low power costs and, above all, its ability to give very high efficiencies with really fine dust particles. Against these there are the large space occupied by the plant and the use of high voltages. Its main draw. back, however, is high capital cost.

All dry methods of cleaning flue gases have one fundamental disadvantage which is of major importance in the case of urban power stations, namely, the fact that no dry method of dust removal will also remove sulphur.

Before the problems associated with the contamination of the atmosphere by sulphur compounds reached their present importance, it was common practice to attempt to increase the efficiency of settling chambers and certain centrifugal separators by using sprays to wet the dust particles and so to increase their settling rate. The disadvantage of the method is that water does not readily adhere to fine dust, and in consequence the quantity of water required is very large indeed, involving not only the cost of providing and 'atomizing' the water but also the disposal of the 'slurry' leaving the plant-a task comparable in magnitude with that of the initial removal of the dust from the flue gases.

In spite of this, spray chambers are now being used on a very large scale, primarily to obtain sulphur removal and incidentally for dust removal. Thus in one large power station in Great Britain, one and a half million cubic feet of flue gases are scrubbed per minute in a system through which they take 30 seconds to pass, and 20 tons of water are pumped through sprays for every ton of coal burned. The slurry is dealt with partly by settling and partly by filtration through sand and rotary filters. The advantage of the system is that high efficiencies can be obtained with regard to both dust and sulphur removal, but against this must be balanced the high cost, the space and plant required and the necessity for large water supplies.

In some plants sprays are replaced wholly or in part by films of water in contact with metal surfaces, a system which still involves the use of large volumes of water and slurry treatment.

During the past few years, a new wet system has been evolved for the removal of dust and sulphur in places where large water supplies are not available. In this 'non-effluent' system, the gases are scrubbed by contact with special arrangements of wooden plates and grids, which are kept wetted by alkaline liquor continuously circulated through the plant. As with other wet systems, the solid matter suspended in the liquor has to be disposed of by settling and filtration, but the main problem, ingeniously overcome, is the prevention of scale formation in the scrubbing towers. 
From this brief review it will be seen that adequate means are available for the prevention of excessive emission of dust and grit into the atmosphere. In the case of very large installations, public opinion has already compelled the use of admittedly expensive methods of dust removal, and there are signs that in the near future, whatever the cost, the demand made upon smaller plants will be more exacting than in the past. There are, however, also indications, both in patent specifications and in the technical press, that increased public interest in atmospheric pollution has given rise to increased experimental work upon its prevention, and it is reasonable to hope that by the time a more rigorous standard is adopted, its cost will not be too heavy a burden upon industry.

\section{Obituary Notices}

\section{Mr. Thomas Crook, O.B.E.}

A LIFE of strenuous and useful work with ripe experience terminated on January 6 when Thomas Crook, principal of the Mineral Resources Department of the Imperial Institute, London, died after an abdominal operation, at the early age of sixty years.

Crook was born at Burnley, in Lancashire, on January 12, 1876. On the examination results of the old Science and Art Department he gained in 1898 a Royal Exhibition to the Royal College of Science for Ireland, where he took the associateship (A.R.C.Sc.I.) in natural science in 1901. He then became assistant in geology to the late Prof. Grenville A. J. Cole. In 1905 he joined the Scientific Department of the Imperial Institute, and for six years (1919-25) he was chief of the Intelligence and Publications Section of the new Imperial Mineral Resources Bureau, which afterwards was incorporated with the Imperial Institute.

Thomas Crook, with his keenness for work and his balanced judgment, early gave promise of being a prominent scientific investigator; but in course of time, his energies became more and more devoted to economic problems in connexion with developing the mineral resources of the Empire. While in Dublin, he described with Grenville Cole rocks dredged from the Atlantic, and devised a method for the mechanical analysis of soils with the well-known Crook's elutriator. In London, under Sir Wyndham Dunstan, excellent mineralogical work was done, and papers were published on geikielite, carnotite, strüverite, ankerite and magnesite, on the electrostatic and electromagnetic soparation of minerals, and on some curious optical properties of certain minerals. A paper with a philosophical bearing was "The Genetic Classification of Rocks and Ore Deposits", which several years later he expanded to form a book, "History of the Theory of Ore Deposits" (1933). Another excellent and useful book is his "Economic Mineralogy" (1921).

This promising scientific work gradually became eclipsed by a vast number of well-written abstracts and articles on the occurrence and possible uses of a great variety of mineral products, which appeared mostly in the Bulletin of the Imperial Institute, but without being keyed to an author's name (with the result that they were not always entered in biblio- graphies, and not easily quoted). With the foundation in 1919 of the Imperial Mineral Resources Bureau, a still more intensive period followed. Then were issued long series of useful pamphlets and books dealing with some fifty different minerals and ores, each complete in itself, and with several editions bringing the statistics up to date. Authoritative statistical volumes of the world's mineral production were also issued annually. Another useful volume, "Minerals of the Empire", was issued for the Wembley Exhibition in 1924. This good work was continued on Crook's return to the Imperial Institute in $\mathbf{1 9 2 5}$ All these publications bear evidence of his influence.

Content in his work, Crook did not strive for honours; but some did come at the end of the chapter. He was made O.B.E. in 1936. In November last he was elected a vice-president of the Mineralogical Society; and in December the honorary degree of B.Sc. was conferred on him by the National University of Ireland.

L. J. S.

\section{Dr. E. E. Prince}

Dr. Edward Ernest Prince died at his residence in Ottawa, Canada, on October 10, at the age of seventy-eight years. A native of Leeds, he graduated from the University of St. Andrews, and taught in the University of Edinburgh and (as professor of biology) at the Royal College of Medicine, Glasgow. $\mathrm{He}$ was one of the group studying the development of fishes under Prof. W. C. McIntosh at the St. Andrews Marine Laboratory. His publications in this field gave him recognition as a fishery specialist, and as such he investigated the fisheries on the east coast of England and the west coast of Ireland.

In 1892 Dr. Prince was appointed commissioner of fisheries for Canada, which position he held until his retirement from active life in 1925. Being responsible for the application of science to fishery problems, he urged in 1894 the establishment in Canada of a marine scientific station, and the support of the Royal Society of Canada and of the British Association at its Toronto meeting in 1896 led to the Canadian Parliament voting the necessary funds in 1898 . He was made director of the new station, which operated with a board of university men to manage it and was 